\title{
MISTURA DE LOTES DE SEMENTES DE MILHO DE DIFERENTES IDADES. 2. EFEITOS SOBRE 0 DESEMPENHO DAS PLANTAS EM CAMPO*
}

S.M. Cícero*

RESUMO: 0 presente trabalho teve como objetivo es tudar os efeitos da mistura de sementes de milho produzi das em duas safras consecutivas (sementes com aproximada mente um ano de idade e sementes novas) sobre o desempenho das plantas em campo. Para tanto, foram utilizadas sementes de 4 cultivares produzidas nos anos agrícolas de 1984/85 e 1985/86; inicialmente, o material mais vetho foi armazenado sob duas condições (ambiente não controlado e cāmara seca) por um período de cerca de 6,5 meses, quando se procedeu, então, a mistura daqueles materiais, nas proporções de $10 \%, 15 \%$ e $20 \%$, com sementes mais novas (safra 1985/86); foram testados também os materiais constituidos por $100 \%$ de sementes produzidas na primeira safra armazenadas nas duas condições já refe ridas e aquele constituido por $100 \%$ de sementes produzíi das na última safra. Concluiu-se que, nas condições do presente trabalho, a mistura de sementes de milho de duas safras subsequentes pode ser uma alternativa viävel para o aproveitamento de sobras não comercializadas,pois a mistura das sementes mais velhas, numa proporção de até $20 \%$ não afetou o desempenho das plantas em campo.

Termos para indexação: mistura de sementes, idade

\footnotetext{
* Trabalho parcialmente financiado pela FINEP.

** Departamento de Agricultura da E.S.A."Luiz de Queiroz" da Universidade de São Paulo - 13.400 - Piracicaba, SP, Bolsista do CNPq.
} 
de sementes, emergencia de plantas, população final de plantas, produção por área.

\section{BLENDING OF CORN SEED LOTS OF DIFFERENT AGES. 2. EFFECTS ON PLANT PERFORMANCE IN THE FIELD.}

ABSTRACT: The objective of this work was to study blending of corn seeds obtained in two consecutive cropping seasons (one year old seeds and new seeds) as to its effects on plant performance in the field. Seeds obtained from 4 cultivars grown in the 1984/85 and 1985/86 cropping seasons were utilized. The older seeds were initially stored under two conditions (noncontrolled environment and dry chamber) for a period of about 6.5 months. Blending was then done to obtain three lots with $10 \%, 15 \%$ and $20 \%$ old seeds, respecti vely. Lots from the two growing seasons were also tested separately. Performance of the various seed lots was evaluated by field observations. The results indicated that corn seeds obtained from two consecutive cropping seasons can be used as a valid alternative for the utilization of commercial surplus for it was observed that blending new seeds with up to $20 \%$ older seeds did not affect plant performance in the field.

Index terms: Seeds blending, seed age, plant emergence, stand, productivity.

\section{INTRODUCĀO}

A utilização de sementes de boa qualidade pelos agricultores é de fundamental importāncia para que se tenha sucesso no estabelecimento da cultura no campo.Pa ra a cultura do milho, as empresas particulares e órgãos públicos tem colocado no mercado, sementes de alta qualidade; entretanto, no caso da produção por empresas 
privadas, hä uma particularidade pouco encontrada para a maioria das outras grandes culturas: as sementes são tratadas com mistura de inseticidas e fungicidas, tornando-as impróprias ao consumo alimentar. Desta forma, no caso de sobras, as sementes são destruidas ou armaze nadas atē a safra seguinte, quando poderão ser comerciā 1 izadas apōs reanālise. Esta segunda opção, contudo, en contra dificuldades na aceitação do produto.

Obviamente, isto representa prejuizo financeiro às companhias produtoras e também um provāvel desperdício de sementes de boa qualidade. Assim, procedimentos que alterassem este panorama, sem afetar a qualidade do produto oferecido aos agricultores, seriam de grande in teresse. Desta forma, o presente trabalho foi conduzido com o principal objetivo de estudar os efeitos da mistura de sementes de milho produzidas em duas safras subsequentes sobre o desempenho das plantas em campo.

$\mathrm{Na}$ literatura consultada foram encontrados trabathos nos quais se estudaram as relações entre a idade das sementes e o desempenho das plantas de milho em cam po; por outro lado, as pesquisas relacionadas à mistura de sementes de diferentes idades não são numerosas.

No que se refere aos efeitos da idade das sementes de milho sobre o desempenho das plantas, DUNGAN \& KOEHLER (1944) verificaram que o decréscimo na produção proveniente de sementes velhas foi causado pela redução da população de plantas por ārea e também devido a menor produção por planta. Os autores observaram que semente com 3 anos de idade proporcionaram redução de $4,8 \%$ na produção em relação às sementes com 1 ano de idade, quando em ambas situações, as populações de plan tas por àrea eram adequadas; quando houve também redução na população, as sementes com 3 anos de idade pro porcionaram perdas de $7,8 \%$ em relação àquelas com 1 ano de idade.

FUNK et alii (1962) verificaram que a qualidade da semente de milho e o subsequente desempenho em campo declinaram com a idade da semente, embora os lotes te- 
nham variado bastante neste aspecto. Por outro lado, FLEMING (1966) não encontrou diferenças significativas no comportamento das sementes de milho $\operatorname{com} 1,2$ e 3 anos de idade.

Em pesquisa conduzida por MARCOS FILHO et alii (1977), com sementes de milho com 1 e 2 anos de idade, foi constatado melhor desempenho, em termos de nümero de espigas e "stand" final para as sementes com 1 ano de idade; por outro lado esta superioridade não foi detectada para produção de grãos.

A utilização de sementes que tiveram uma deterioração causada pela idade (envelhecimento) é apontada por FILGUEIRAS (1981) como sendo uma das causas da baixa população de plantas por ärea. Por outro, MATTHEWS (1985) afirrmou que hä muitos relatos sobre o desempe nho de sementes velhas, provenientes de lotes de alta qualidade, que originaram plântulas menores quando comparadas com as plântulas provenientes de sementes novas.

Coin relação à mistura de sementes de milho de diferentes idades, CAMPOS (1979) trabalhou com sementes dos híbridos comerciais AG $162 / 5$ e HMD 7974 , produzidas nas safras de $1976 / 77$ e $1977 / 78$ e testou as misturas das sementes nas proporções de $10 \%$ e $26 \%$ das sementes mais velhas com $90 \%$ e $74 \%$, respectivamente, das semen tes mais novas, comparando-se com os materiais consti = tuídos por $100 \%$ de sementes de cada uma das duas safras; o autor não detectou diferenças de produção entre - tratanento constituido por $100 \%$ de sementes da ültima safra (semenzes mais novas) com aquele: constituido por $10 \%$ de sementes velhas misturadas com $90 \%$ de sementes novas. Nun segundo experimento conduzido por CAMPOS (1980), foram testado: os mesmos hibridos, prcdu zidos nas safras $1976 / 77,1977 / 78$ e 1978/79, com os mes mos tratamentos que no caso anterior; os resultados obtidos nos dois aros de experimentação (mistura de semen tes das safcas $1976 / 77 \mathrm{com} 1977 / 78$ e das safras $1977 / 7 \overline{8}$ com 1978/79) foram idênticos aos cbtidos no primeiro ex perimento. 
Por outro lado, CICERO (1987) estudou a mistura de sementes dos hỉbridos AG 162, AG 401, Contimax 133 e C115 nas proporções de $10 \%, 15 \%$ e $20 \%$ dos materiais produzidos na safra 1983/84 com aqueles produzidos em $1984 / 85$ e concluiu que a emergencia de plântulas e a pro dução de grãos não foram afetadas pela mistura de sementes, nas proporções estudadas, das duas safras.

\section{MATERIAL E METODOS}

0 experimento de campo foi conduzido em dois locais: na ārea experimental do Departamento de Agricultura da Escola Superior de Agricultura "Luiz de Queiroz"(LAG/ ESALQ), em Piracicaba, SP e em área experimental pertencente à empresa Sementes Agroceres S/A., localizada em Santa Cruz das Palmeiras, SP.

Foram utilizados quatro cultivares (híbridos duplos comerciais AG 162, AG 401, Contimax 133 e C 115) e que serão designados daqui por diante como A, B, C e D . Inicialmente foram obtidos, em dezembro de 1985, dois sa cos de sementes de $40 \mathrm{~kg}$ cada um, para cada cultivar, produzidos na safra 1984/85 e que representaram a "sobra" de sementes da referida safra (primeira safra).

As sementes dos cultivares A, B e D eram classificadas por largura (peneira 22/64") e tinham sido tratadas com uma mistura do fungicida captan 75 e os insetici das deltametrina $2,5 \%$ + butóxido de piperonila $10 \%$ e malathion 100E enquanto o cultivar C tinha suas sementes classificadas como peneira 20/64" e tratadas com uma mistura do fungicida PCMB $24 \%$ + etridiozol $6 \%$ e os inseticidas malathion $100 \mathrm{E}$ e perimifós metỉlico $50 \%$.

Com a finalidade de avaliar a qualidade inicial do referido material, as sementes provenientes dos dois sacos de cada cultivar, foram misturadas e homogeneizadas e retiraram-se amostras com as quais foram conduzidos testes de germinação. Desta forma, as sementes dos culti vares A, B, C e D apresentaram, respectivamente, $96 \%$, 
94\%. $88 \%$ e $98 \%$ de germinação.

Após a retirada das amostras para a avaliação da qualidade inicial, as sementes de cada cultivar foram di vididas em duas partes iguais $(40 \mathrm{~kg})$, colocadas de volta nas embalagens originais (sacos de papel multifoliado) e armazenadas em dois ambientes: uma das partes em condições de ambiente de laboratório do LAG/ESALQ e que passa a ser designada de LAB/85 e a outra em cámara seca pertencente ao laboratório de Análises de Sementes do LAG/ESALQ, a $35 \%$ de umidade relativa do ar e temperatura média de $23^{\circ} \mathrm{C}$, a qual foi designada de CS/85. Ambos os materiais permaneceram nas referidas condições por um período de aproximadamente 6,5 meses (20/12/1985 a $31 / 07 / 1986)$. Ao final desse período, foram conduzidos testes de germinação, que acusaram os seguintes valores: para o cultivar A, $96 \%$ e $95 \%$ (respectivamente para as sementes LAB/85 e CS/85); para o cultivar B, $90 \%$ e $95 \%$ (respectivamente para as sementes $\mathrm{LAB} / 85$ e CS/85); para o cultivar C, $77 \%$ e $86 \%$ (respectivamente para as sementes LAB/85 e CS/85) e para o cultivar D, 96\% e $97 \%$ (respectivamente para as sementes LAB/85 e CS/85).

Em junho de 1986 foram obtidos mais dois sacos de sementes ( $40 \mathrm{~kg}$ cada um), para cada cultivar, produzidas na safra 1985/86 e que representaram as sementes da $\overline{1} 1-$ tima safra, ou seja, aquelas que seriam normalmente comercializadas no ano de 1986. As sementes desta safra apresentavam as mesmas características, quanto à classificação pela largura, daquelas obtidas na safra 1984/85 e tamberm haviam sido tratadas com os mesmos produtos.

Os dois sacos de sementes de cada cultivar foram tambëm misturados e homogeneizados para que, posterior mente, fossem retiradas amostras visando a avaliação da qualidade inicial do referido material; para tanto foram conduzidos testes de germinação que revelaram para os cultivares A, B, C e D, respectivamente, os valores de $98 \%, 94 \%, 97 \%$ e $98 \%$ de germinação.

A mistura das sementes produzidas nas duas safras foi realizada com base no peso de mil sementes; assim, calculava-se o peso de cada material que deveria 
ser misturado ao outro, conforme as proporções desejadas, ou sejam $10 \%, 15 \%$ e $20 \%$ em peso das sementes da safra $1984 / 85 \mathrm{com}$, respectivamente, $90 \%$, $85 \%$ e $80 \%$ em peso das sementes produzidas na safra 1985/86. Desta forma, em 01/07/1986, foram constituídos os tratamentos para cada um dos cultivares em estudo (Tabela 1 ).

Tabela 1. Constituição dos tratamentos para cada um dos cultivares.

\begin{tabular}{|c|c|c|c|c|}
\hline \multirow{2}{*}{\multicolumn{2}{|c|}{ Tratamentos }} & \multicolumn{3}{|c|}{$\begin{array}{l}\text { Composição das misturas por } \\
\text { safra/condição de armazena } \\
\text { mento }(\%)\end{array}$} \\
\hline & & $\begin{array}{c}84 / 85 \\
(\mathrm{LAB} / 85)\end{array}$ & $\begin{array}{c}85 / 86 \\
(\mathrm{LAB} / 86)\end{array}$ & $\begin{array}{c}84 / 85 \\
(\mathrm{CS} / 85)\end{array}$ \\
\hline 1. & $100 \% \mathrm{LAB} / 85$ & 100 & - & - \\
\hline 2 . & $100 \%$ LAB / 86 & - & 100 & - \\
\hline 3. & $100 \% \mathrm{CS} / 85$ & - & - & 100 \\
\hline 4. & $10 \% \mathrm{LAB} / 85+90 \% \mathrm{LAB} / 86$ & 10 & 90 & - \\
\hline 5. & $15 \% \mathrm{LAB} / 85+85 \% \mathrm{LAB} / 86$ & 15 & 85 & - \\
\hline 6 . & $20 \% \mathrm{LAB} / 85+80 \% \mathrm{LAB} / 86$ & 20 & 80 & - \\
\hline 7 . & $10 \% \mathrm{CS} / 85+90 \% \mathrm{LAB} / 86$ & - & 90 & 10 \\
\hline 8. & $15 \% \mathrm{CS} / 85+85 \% \mathrm{LAB} / 86$ & - & 85 & 15 \\
\hline 9 . & $20 \% \mathrm{CS} / 85+80 \% \mathrm{LAB} / 86$ & - & 80 & 20 \\
\hline
\end{tabular}

Após a mistura e a homogeneização, cada uma das amostras (parcelas) foi embalada em sacos de papel multi foliado, com capacidade de $5 \mathrm{~kg}$, e armazenada, em condi ções normais de ambiente do Laboratório de Análise de Sementes do LAG/ESALQ, onde permaneceu até a data da instalação dos experimentos no campo.

Um dos experimentos de campo foi instalado em so1o, pertencente ao Grande Grupo Terra Roxa Estruturada, no município de Piracicaba, SP. O preparo da ärea constou de uma aração e uma gradagem e na véspera da instala ção do experimento foi realizada a adubação mineral, em sulcos espaçados de $1,0 \mathrm{~m}$ e que constou da aplicação de 
$12 \mathrm{~kg}$ de $\mathrm{N} / \mathrm{ha}, 60 \mathrm{~kg}$ de $\mathrm{P}_{2} \mathrm{O}_{5} / \mathrm{ha}$ e $30 \mathrm{~kg}$ de $\mathrm{K}_{2} \mathrm{O} / \mathrm{ha}$; juntamente com o adubo foi distribuido o inseticida granulado carbufuran $5 \% \mathrm{G}$ na dosagem de $30 \mathrm{~kg}$ do produto comercial/ha. No dia 02/12/1986 foi realizada a semeadura em covas, abertas ao lado do sulco que tinha recebido a mistura do adubo com o inseticida, espaçadas de $40 \mathrm{~cm}$ na linha e de $1,0 \mathrm{~m}$ nas entre-linhas. Foi utilizado o delineamento de blocos casualizados, com 4 repetições, sendo cada parcela constituida por uma linha de $10 \mathrm{~m}$ de comprimento, a qual comportava, portanto, $25 \mathrm{co}$ vas; dessa maneira, a área de cada parcela compreendeu $10 \mathrm{~m}^{2}$. A quantidade de sementes distribuídas nas 25 co vas de cada parcela foi estabelecida em função dos dados de germinação obtidos para cada tratamento na época da semeadura (novembro de 1986), com o objetivo de se obter, após a emergência, uma população de, aproximadamente 50 plantas por 10 metros lineares. Aos 38 dias após a semeadura, efetuou-se a adubação nitrogenada em cobertura, tendo sido distribuído $60 \mathrm{~kg}$ de $\mathrm{N} / \mathrm{ha}$. Alëm da adubação nitrogenada em cobertura, foram dispensados às plantas os tratos culturais necessários ao seu desenvolvimento adequado, como capinas manuais (em $19 / 12 / 1986$ e 07/01/1987) e uma aplicação do lagarticida granulado carbaril $10 \mathrm{~g} / \mathrm{kg}$, na dosagem de $20 \mathrm{~kg}$ do produto comercial/ha (em 08/01/1987).

0 outro experimento foi instalado em Latossolo Roxo, no municipio de Santa Cruz das Palmeiras. O preparo da área e a instalação do experimento, em $12 / 12 / 1986$, foram realizados de maneira semelhante ao experimento de Piracicaba. A adubação mineral, realiza da na véspera da instalação do experimento, constou dá aplicação de $12 \mathrm{~kg}$ de $\mathrm{N} / \mathrm{ha}, 90 \mathrm{~kg}$ de $\mathrm{P}_{2} \mathrm{O}_{5} / \mathrm{ha}$ e $48 \mathrm{~kg}$ de $\mathrm{K}_{2} \mathrm{O} / \mathrm{ha}$; juntamente com o adubo foi distribuído o inseticida granulado carbufuran $5 \% \mathrm{G}$ na dosagem de $40 \mathrm{~kg}$ do produto comercial/ha. Aos 25, 45 e 60 dias após a semeadura, efetuaram-se as adubações nitrogenadas em cobertura, tendo sido distribuỉdos, em cada uma delas $54 \mathrm{~kg}$ de $\mathrm{N} / \mathrm{ha}$. Os outros tratos culturais constaram de uma capina mecânica (em 18/01/1987) e duas aplicações 
do Lágarcicida granulado carbaril $10 \mathrm{~g} / \mathrm{kg}$, na dosagem de $20 \mathrm{~kg}$ do produto comercial/ha em cada aplicação (em 06/01/1987 e 26/01/1987).

Antes da colheita, realizada em 29/04/1987 para o experimento de Piracicaba e em 22/05/1987 para o experi mento de Santa Cruz das Palmeiras, foram realizadas as seguintes determinações:

a. porcentagem de emergēncia das plantas em cada parcela, realizada en $31 / 12 / 1986$ para o experimento de Piracicaba e em 08/0 $1 / 1987$ para o experimento de Santa Cruz das Palmeiras;

b. número final de plantas em cada parcela, realizada em 27/04/1987 e 21/05/1987, respectivamente para os experimentos de Piracicaba e Santa Cruz das Palmei ras;

c. numero de plantas quebradas e/ou acamadas em ca da parcela, realizada em $27 / 04 / 1987$ e $21 / 05 / 1987$, res pectivamente para os experimentos de Piracicaba e Santa Cruz das Palmeiras.

A colheita dos dois experimentos, constou da coleta e despalha de todas as espigas de cada parcela, incluindo-se aquelas que se apresentavam danificadas por insetos e/ou microorganismos. No mesmo dia da colheita foram realizadas as seguintes determinações:

a. número de espigas sadias em cada parcela;

b. nümero de espigas danificadas por insetos e/ou microorganismos em cada parcela.

A ültima determinação efetuada foi o peso de grãos por parcela e para tanto, procedeu-se da seguinte mane ra: as espigas sadias e as frações sadias daquelas que se apresentavam danificadas por insetos e/ou microorganismos foram debulhadas manualmente e, em seguida, procedeu-se a pesagem dos grãos, em balança com sensibilidade de centésimos do quilograma; os grãos tiveram seus pesos corrigidos para a umidade de $13 \%$ através da fórmu la indicada por TAVARES (1972). 
Para a anālise estatística utilizou-se o delineamento blocos casualizados, com 4 repetições; para tanto os dados correspondentes às porcentagens de emergéncia das plantas foram transformados em arc sen $\sqrt{\text { porcentagem/100 }}$ os de nümero final de plan tas quebradas e/ou acamadas, número de espigas sadias e número de espigas danificadas por insetos e/ou microorganismos em $\sqrt{x+0,5}$, enquanto os de peso de grãos não sofreram transformações. Onde se fez necessário foi aplicado o teste de Tukey para o confronto entre as médias ao nivel de $5 \%$ de probabilidade, obtendo-se a dife rença minima significativa.

\section{RESULTADOS E DISCUSSÃO}

Nas Tabelas 2 e 3 são apresentadas as médias obtidas para os tratamentos nas determinações de emergência das plantas, número final de plantas, número de plantas quebradas e/ou acamadas, número de espigas sadias, número de espigas danificadas por insetos e/ou microorganismos e peso de grãos nos experimentos conduzidos, respectivamente, em Piracicaba e Santa Cruz das Palmeiras para o cultivar A. Em resumo, para este cultivar, observou-se que o desempenho das plantas provenientes do material re sultante da mistura de sementes das duas safras não sé diferenciou estatisticamente do material constituido exclusivamente por sementes da ültima safra (sementes novas).

Nas Tabelas 4 e 5 são apresentadas as médias obtidas para os tratamentos nas diferentes determinações rea lizadas, respectivamente, em Piracicaba e Santa Cruz das Palmeiras para o cultivar B.Em resumo, para este cultivar observou-se que o desempenho das plantas provenientes do material resultante da mistura de sementes das duas safras não se diferenciou estatisticamente do material constituỉdo exclusivamente por sementes da $\vec{u} 1 t i m a$ safra (sementes novas).

Nas Tabelas 6 e 7 são apresentadas as médias obti- 

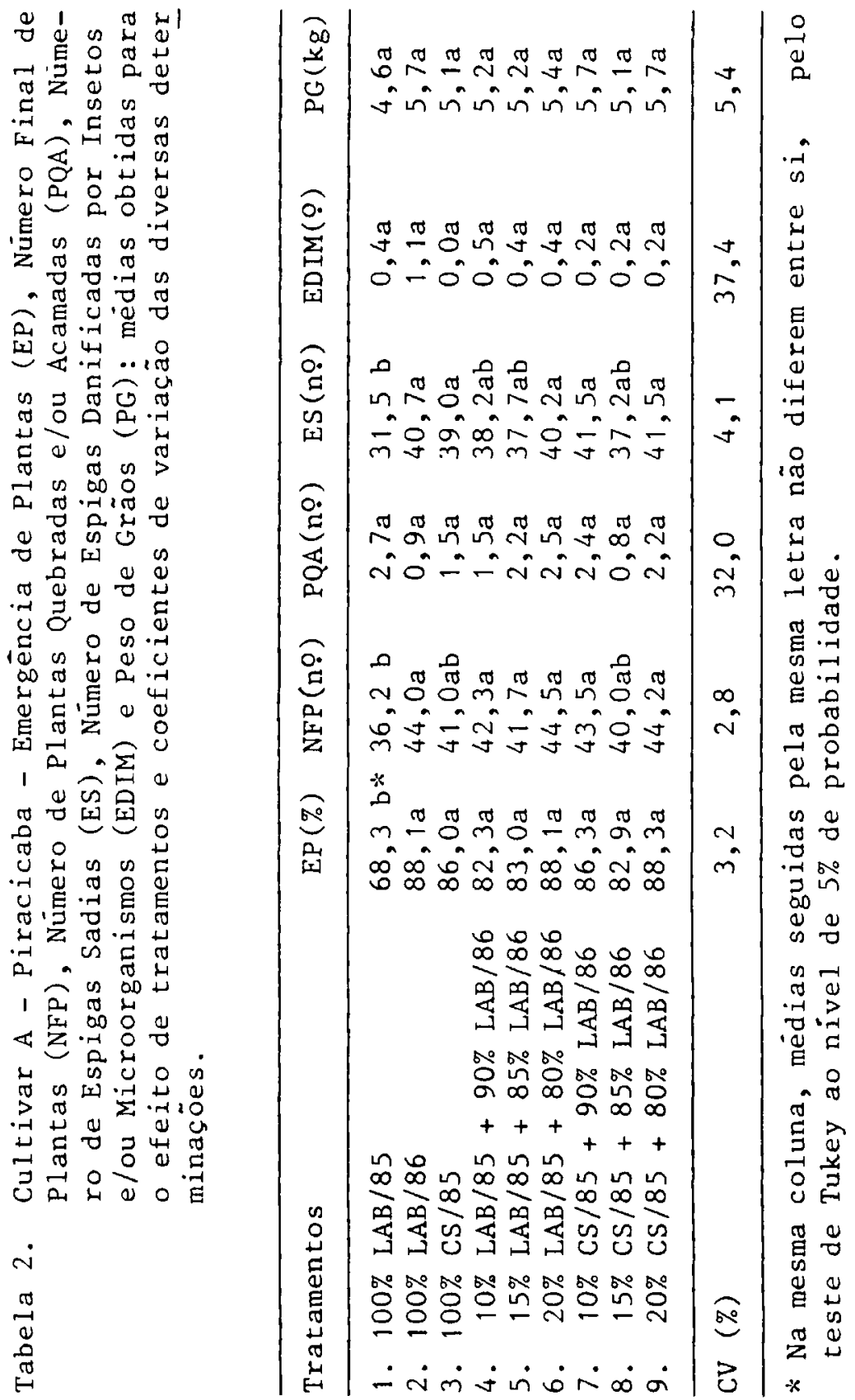


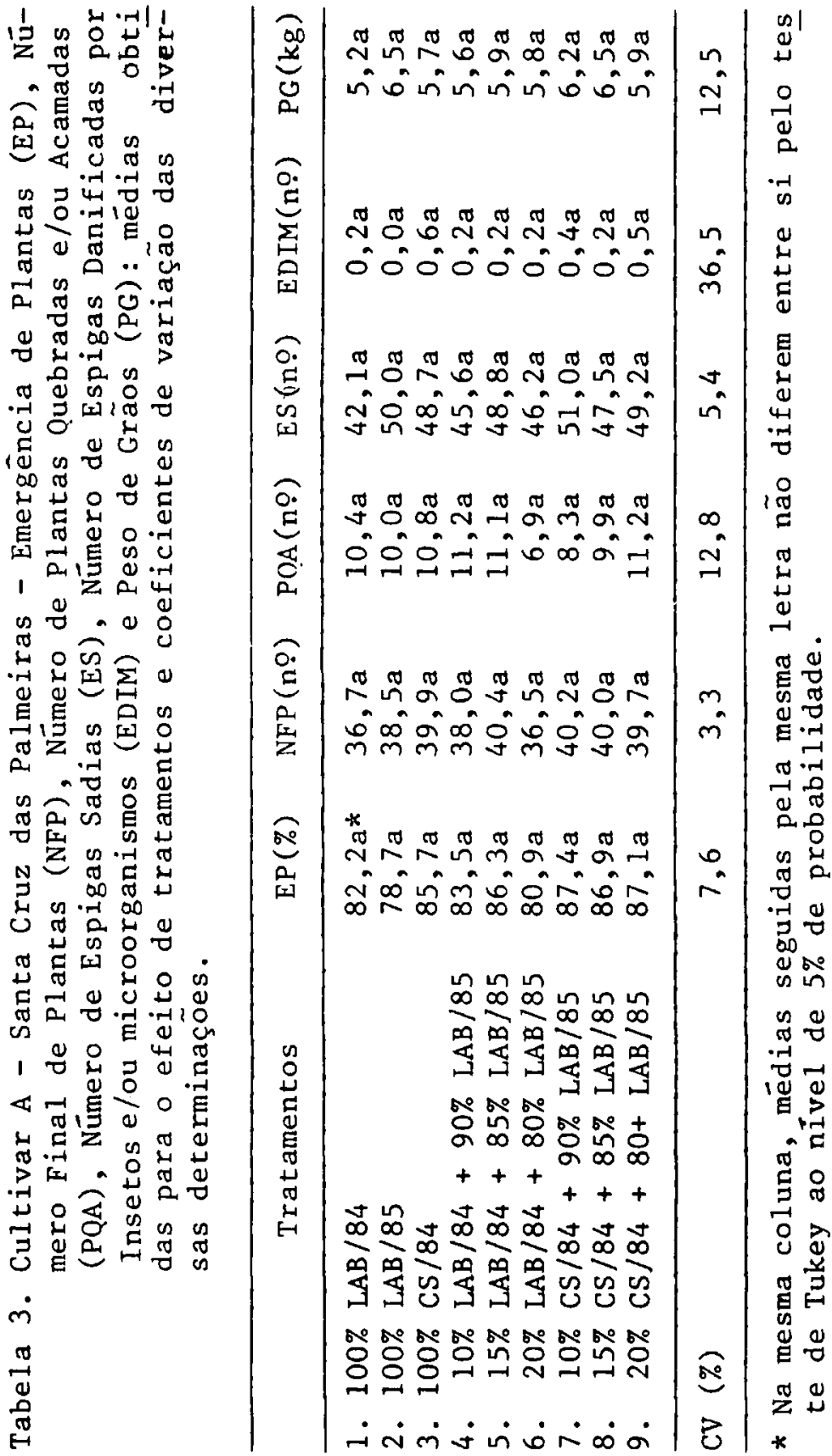




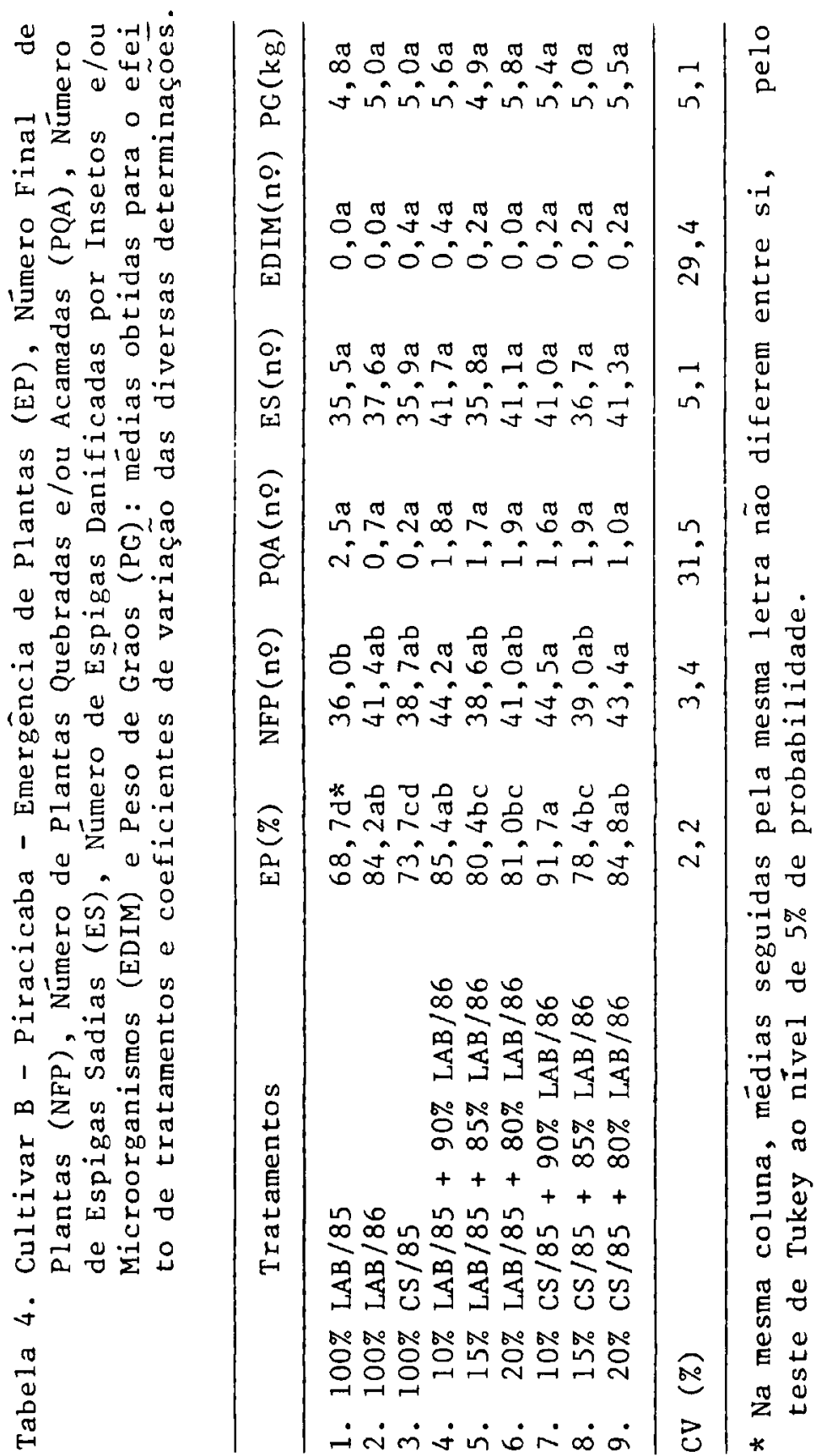




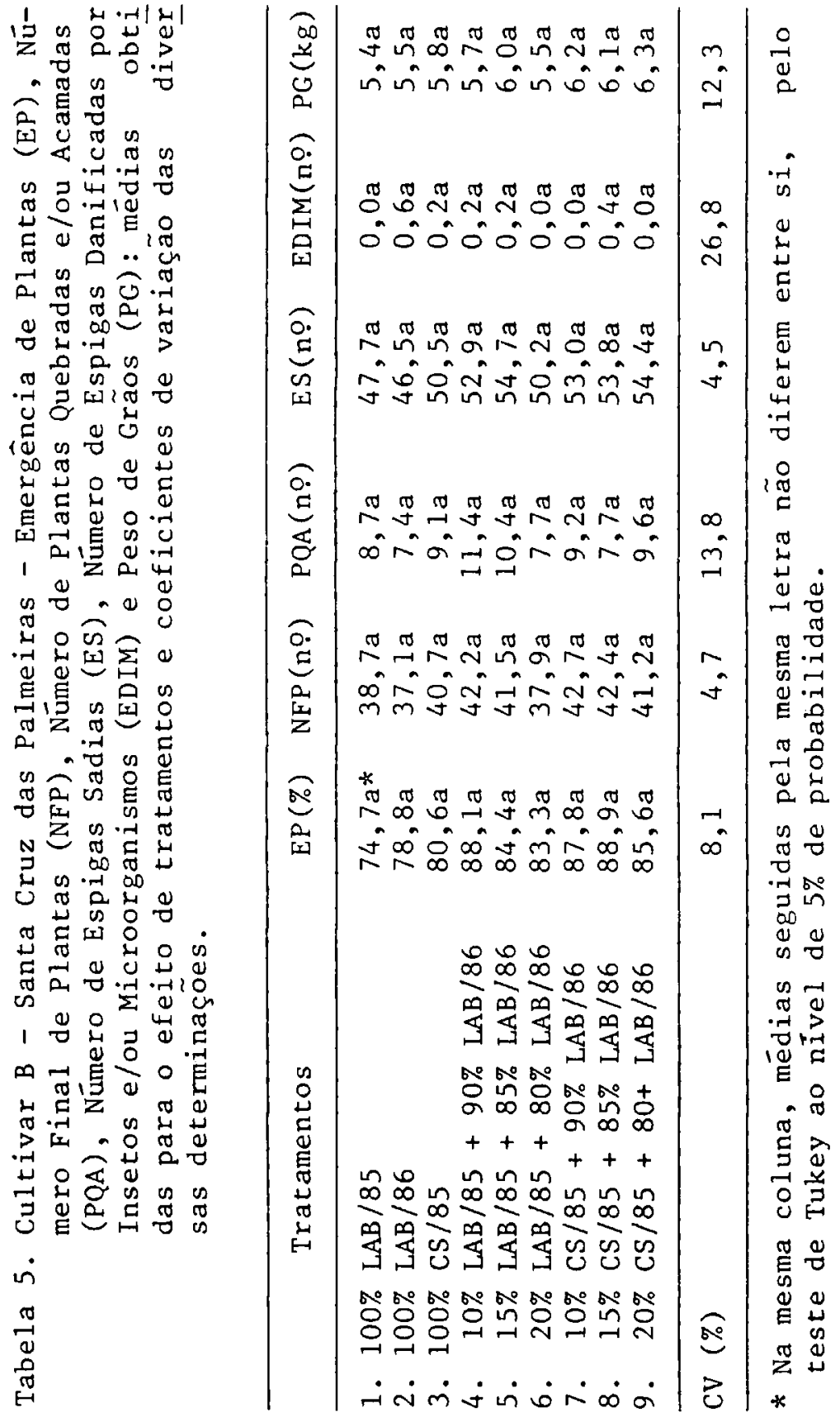




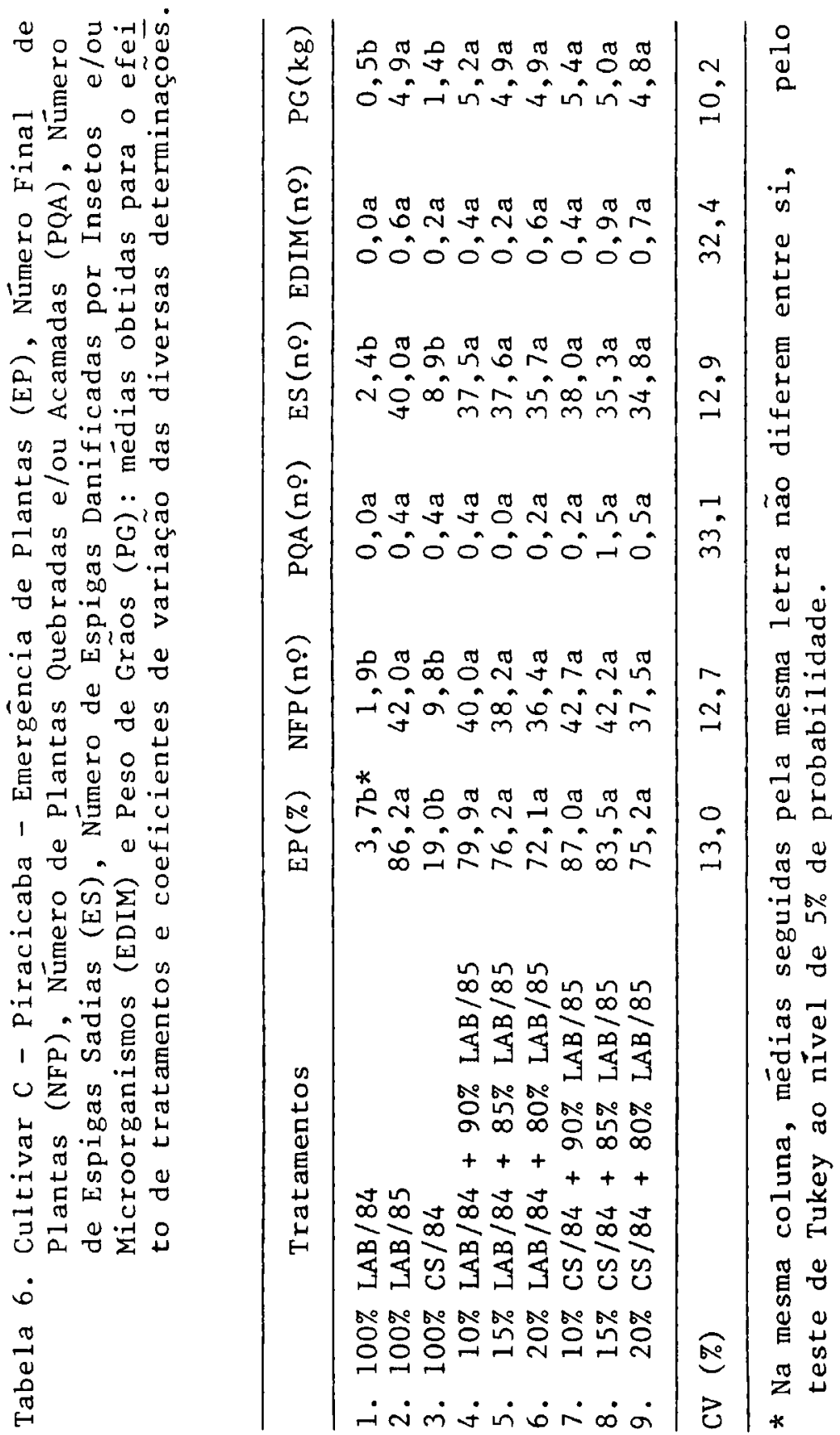




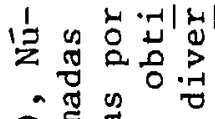

คิ

A

¿

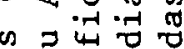

$\pi 0 .-10$

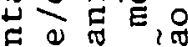

ส

-

ठ

感

0 in

क क 0

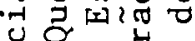

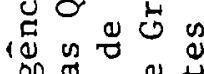

㝳

a 5 o

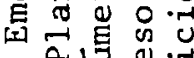

A 灵品

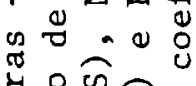

.

吃然

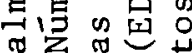

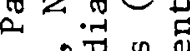

us $\infty$ o :

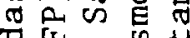

Z

$N \leftleftarrows \pi$

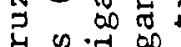

บ 劣 की

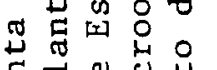

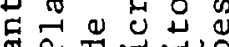

की $\Sigma$ व

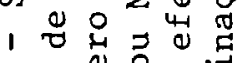

৩ $-\stackrel{\Xi}{\Xi} \circ \circ$

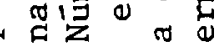

两

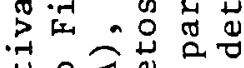

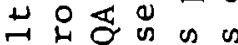

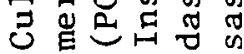

永

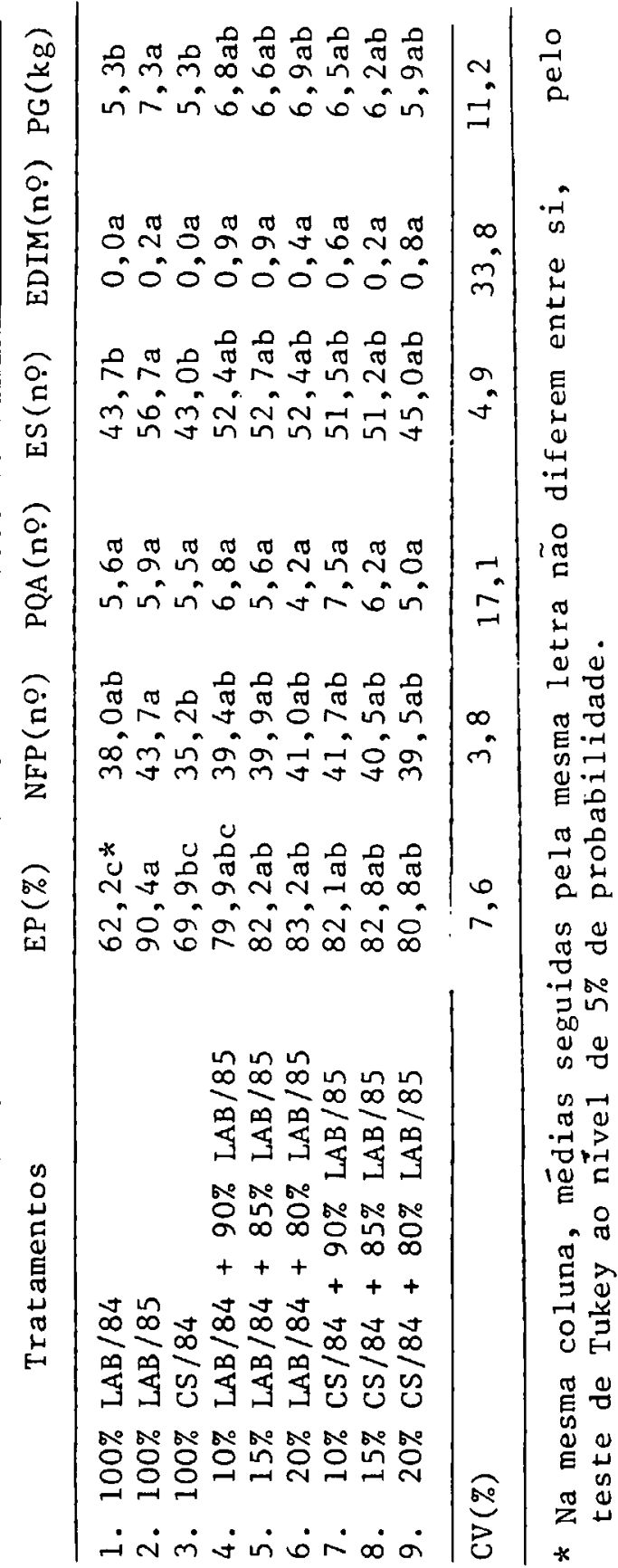


das para os tratamentos nas diferentes determinações rea] izadas, respectivamente, em Piracicaba e Santa Cruz das Palmeiras para o cultivar C. Em resumo, para este cultivar, observou-se que o desempenho das plantas prove nientes do material resultante da mistura de sementes das duas safras não se diferenciou estatisticamente do material constituido exclusivamente por sementes da última safra (sementes novas).

Nas Tabelas 8 e 9 são apresentadas as médias obtidas para os tratamentos nas diferentes determinaçöes rea lizadas, respectivamente, em Piracicaba e Santa Cruz das Palmeiras para o cultivar D. Em resumo, para este cultivar, observou-se que o desempenho das plantas provenientes do material resultante da mistura de sementes das duas safras não se diferenciou estatisticamente do material constituído exclusivamente por sementes da ültima safra (sementes novas).

O exame das Tabelas 2 a 9 permite verificar que 0 comportamento dos tratamentos, para os 4 cultivares nos 2 locais, foi semelhante para a maioria dos parâmetros estudados. Desta forma, no caso da emergência em campo e número final de plantas não se observaram diferenças significativas entre os tratamentos para os cultivares $A$ e B no experimento conduzido em Santa Cruz das Palmeiras e para o cultivar D em ambos os locais. Por outro lado, para os cultivares A e B no experimento conduzido em Piracicaba e para o cultivar $C$, nos dois locais, geral mente foi observado comportamento semelhante entre os tratamentos constituídos por sementes da safra 1984 ! 85 (sementes velhas) porém, apenas as sementes daquela safra armazenadas em ambiente de laboratório proporcionaram desempenho de plantas inferior aos demais tratamen tos.

0 exame das Tabelas $2,3,4,5,8$ e 9 permite verificar que para os cultivares $A$, B e D, a emergencia foi muito boa (acima de $80 \%$ para a maioria dos tratamentos), atestando a boa qualidade fisiológica do material utilizado; em função disto, o nümero final de plantas foi satisfatório para a maioria dos tratamentos. Por 


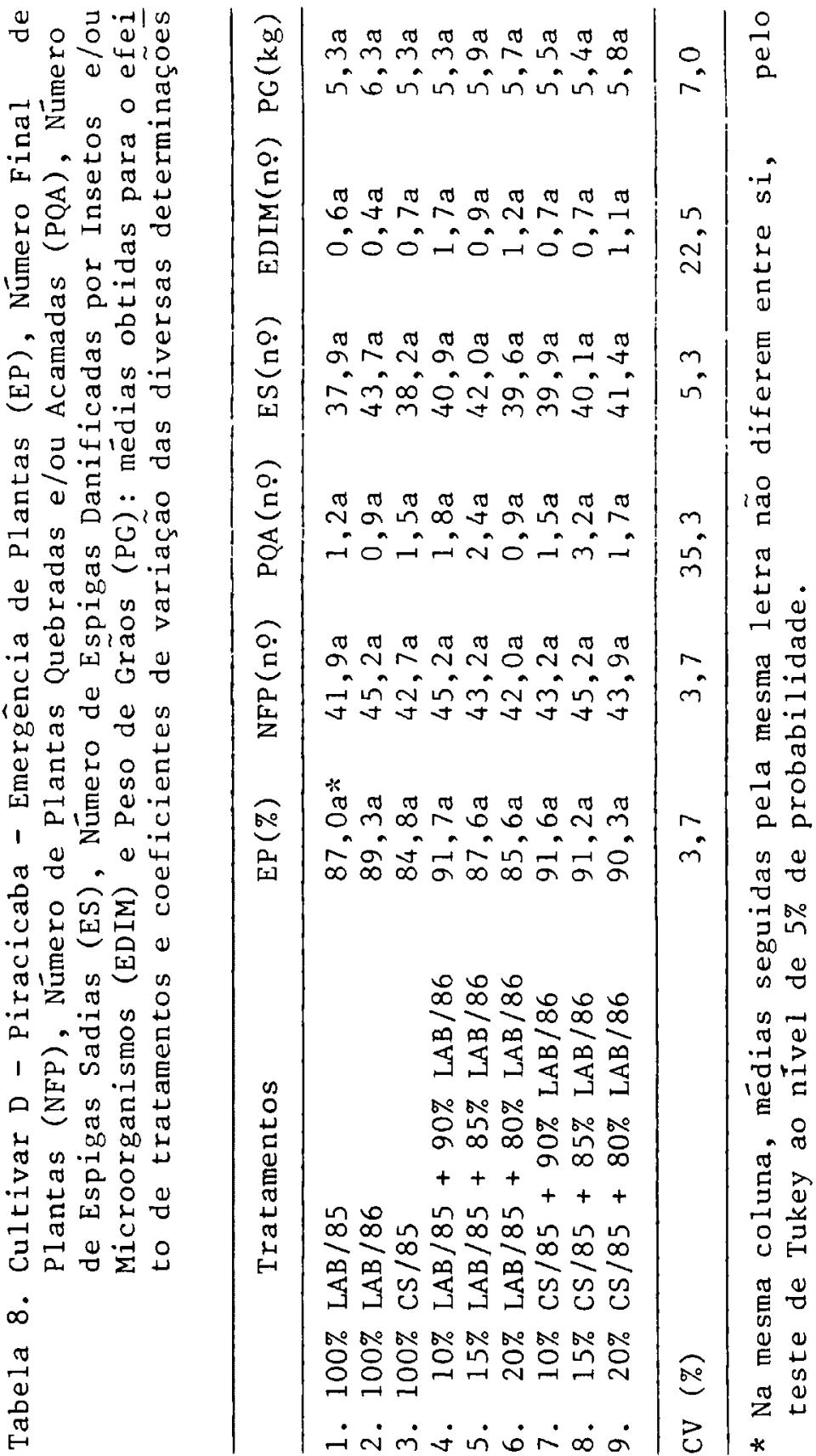




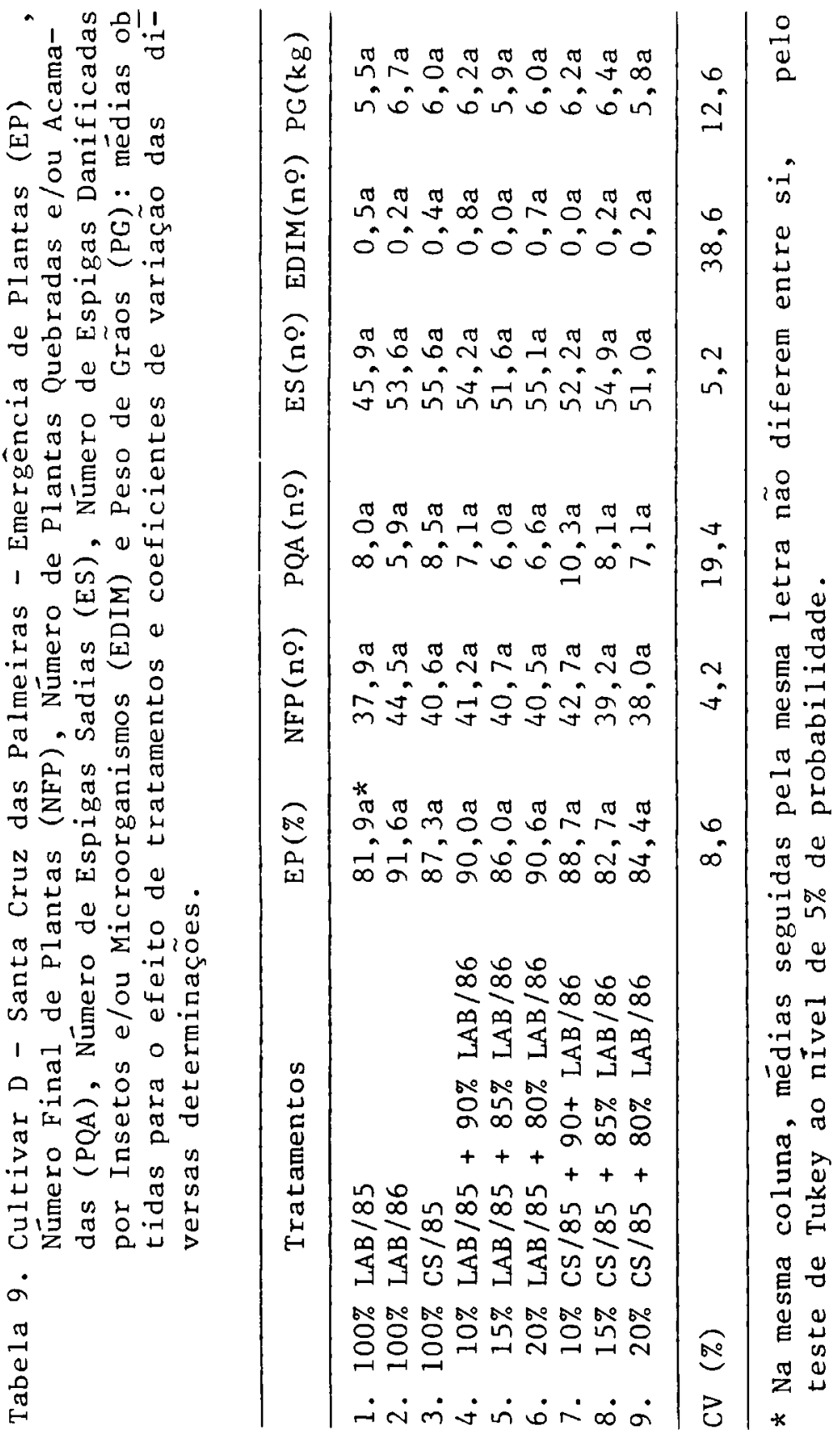


outro lado, para o cultivar C (Tabelas 6 e 7), a emergên cia jâ não apresentou desempenho tão bom quanto ao dos outros cultivares, principalmente para os tratamentos constituidos exclusivamente por sementes da safra 1984 / 85 (sementes velhas); entretanto, o número final de plan tas pode ser considerado satisfatório para a maioria dos tratamentos, uma vez que a quantidade de sementes utilizadas na semeadura foi comparativamente maior do que a dos outros cultivares, pois para tanto levou-se em conta a porcentagem de germinação das sementes de cada tratamento.

$\bar{E}$ importante se destacar que o material resultante da mistura de sementes das duas safras, nas três proporções estudadas, apresentou emergência e número final de plantas semelhantes ao material constituido exclusivamen te por sementes da ültima safra (sementes novas) para os 4 cultivares em estudo, corroborando os resultados ob tidos por CICERO(1987). Por outro lado, não houve diferenças significativas entre as sementes das duas safras (sementes novas e sementes com aproximadamente 1 ano de idade) para os cultivares A e B no experimento de Santa Cruz das Palmeiras e D nos 2 locais de experimenta ção; resultados semelhantes foram obtidos por FLEMING (1966), CAMPOS (1979), CAMPOS (1980) e CICERO (1987) . Entretanto, para os cultivares A e B no experimento de Piracicaba e cultivar $C$ nos dois locais, foram constatadas menores porcentagens de emergência para sementes com aproximadamente 1 ano de idade armazenadas em ambiente não controlado em relação às sementes novas, corroborando os resultados obtidos por DUNGAN \& KOEHLER (1944) , MARCOS FILHO at alii (1977), FILGUEIRAS (1981) e CICERO (1987), que tambēm constataram melhor desempenho para se mentes novas em relação àquelas com 1 ou mais anos de idade.

Com relação às determinações de plantas quebradas e/ou acamadas, espigas sadias e espigas danificadas por insetos e/ou microorganismos não se observaram diferen ças significativas entre os tratamentos, para os 4 cult $\bar{i}$ vares estudados, a não ser no caso do número de espigas 
sadias, onde foi constatado, para o cultivar A, valor in ferjor para o tratamento 1 em relação aos tratamentos 2, $3,6,7$ e 9, no experimento de Piracicaba e para o culti var $C$, onde se observaram valores inferiores para os tratamentos 1 e 3 em relação aos demais no experimento de Piracicaba e do tratamento 3 em relação ao 2, no experimento de Santa Cruz das Palmeiras. Resultados seme1hantes foram observados por CAMPOS (1979), CAMPOS(1980) e CICERO (1987).

Tal como aconteceu com as demais determinações de campo, o peso de grãos não foi afetado pela mistura de sementes das duas safras. Apenas para o cultivar C, foi observado menor produção de grãos para os tratamentos 1 e 3 em relação aos demais, no experimento de Piracicaba, e dos mesmos tratamentos em relação ao tratamento 2, no experimento de Santa Cruz das Palmeiras. Estes resultados corroboram aqueles obtidos por CAMPOS (1979), CAM POS (1980) e CICERO (1987).

\section{CONCLUSÕES}

Nas condições do presente trabalho, a mistura de sementes de milho de duas safras subsequentes pode ser uma alternativa viável para o aproveitamento de sobras não comercializadas, pois a mistura das sementes mais ve lhas, numa proporção de até $20 \%$, não afetou o desempenhō das plantas em campo.

\section{REFERENCIAS BIBLIOGRAFICAS}

CAMPOS, M.S. Experimento de caldeamento. Sementes Agro ceres S.A./Departamento de Pesquisa, Santo Antonio da Platina, 1979. 7p.

CAMPOS, M.S. Experimento de caldeamento. Sementes Agro ceres S.A./Departamento de Pesquisa, Santo Antonio da Platina, 1980. 19p.

CICERO, S.M. Mistura de lotes de diferentes idades e 
sua relação com a qualidade fisiológica e sanidade das sementes e desempenho das plantas de milho (Zea mays L.). Piracicaba, 1987. 119p. (Livre-Docência Escola Superior de Agricultura "Luiz de Queiroz" / USP) .

DUNGAN, G.H. \& KOEHLER, B. Age of seed corn in relation to seed infection and yielding capacity. Joumal of the American Society of Agronomy, Washington, 36(4) : 436-43, 1944.

FILGUEIRAS, T.S. Seed vigor and productivity. Pesquisa Agropecuária Brasileira, Brasília, 16(6):851-4,1981.

FLEMING, A.A. Effects of seed age, producer, and storage on corn (Zea mays L.) production. Agronomy Journal, Madison, 58:227-8, 1966.

FUNK, C.R.; ANDERSON, J.C.; JOHNSON, N.W.; ATKINSON, R . $W$. Effect of seed source and seed age on field and laboratory performance of field corn. Crop Science, Madison, 2(4):318-20, 1962 .

MARCOS FILHO, J.; SILVA, A.E.; CICERO, S.M.; GONÇALVES , C.A.R. Efeitos do tamanho da semente sobre a germina ção, o vigor e a produção de milho (Zea mays L.) . Anais da Escola Superior de Agricultura "Luiz de Queiroz", Piracicaba, 34:327-37, 1977.

MATTHEWS, S. Physiology of seed ageing. Outlook on Agriculture, Bracknel1, 14(2):89-95, 1985.

TAVARES, F.C.A. Componentes de produção relacionados à heterose em híbridos intervarietais de milho (Zea mays L.). Piracicaba, 1972. 106 p. (Doutoramento Escola Superior de Agricultura "Luiz de Queiroz" / USP.

Recebido para publicação em: 27.10 .88

Aprovado para publicação em: 13.03 .89 